\title{
BIBLIOGRAFÍA DE MUDÉJARES Y MORISCOS, I
}

\author{
Míkel de Epalza y Luis F. Bernabé Pons
}

${ }^{\mathrm{c} A B D}$ AL-RAHMĀN, Ŷamal

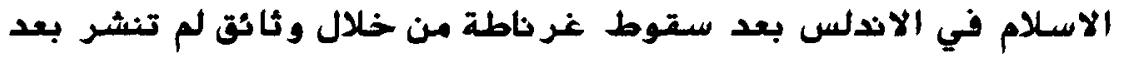

en: Mélanges Louis Cardaillac, II.133-146.

[«El islam en al-Andalus desde la caída de Granada a través de documentos inéditos». El autor analiza, basándose en varios manuscritos moriscos inéditos de la Biblioteca Nacional de Madrid, la religiosidad de los moriscos y divide los textos entre los que son islámicamente correctos y aquéllos que introducen interpretaciones erróneas. También estudia sus particularidades lingüísticas como el defectuoso nivel de lengua árabe y las interferencias de la lengua española] E.L.G.

${ }^{\mathrm{c} A B D} \mathrm{AL}-{ }^{\mathrm{c}} \mathrm{AZZ \overline {I }} \mathrm{Z}$, Saher

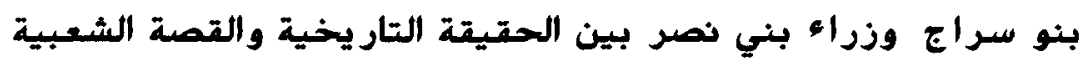

en: Mélanges Louis Cardaillac, II.49-95.

[«Los Abencerrajes, ministros de los nazaríes, entre la verdad histórica y la leyenda popular». En primer lugar se efectúa un acercamiento histórico a la familia desde sus orígenes hasta la etapa granadina y morisca. En la segunda parte se hace un recorrido por las novelas históricas -españolas y francesas- en las que se encuentran los Abencerrajes y se presentan las opiniones de los especialistas sobre la aparente contradicción que existe entre la imagen sublimada de los Abencerrajes que aparece en las novelas en contraposición al duro trato otorgado a los moriscos] E.L.G.

ABDEL-LATIF, Serry Muhammad, «Influencias del árabe en un texto morisco inédito», en: Mélanges Louis Cardaillac, I.21-48.

[Ejemplificación de arabismos sintácticos y semánticos del ms. aljamiado 5354 según el modelo de análisis de Galmés de Fuentes] L.B.P.

ALEMANY GARCíA, Salvador, «Forna: entre la vespra i l'endemà de l'expulsió», Aguaits, Denia, 10, 1994, 23-38. 
[Estudio del poblamiento morisco de la Baronía de Forna, cerca de Denia, y de las consecuencias de su expulsión en 1609. Ilustraciones] M.E.

ALVARO ZAMORA, María Isabel, «El trabajo en los alfares mudéjares aragoneses. Aportación documental acerca de su obra, controles de su producción y formas de comercialización y venta», Revista de Historia "Jerónimo Zurita", Zaragoza, 65-66 (1992):97-138.

[Trabajo muy documentado sobre el funcionamiento de los alfares aragoneses desde el siglo XV. La mayoría de las noticias y documentos recogidos se refieren al período morisco] L.B.P.

ANDÚJAR CASTILLO, Juan, «Entre la 'ađministración' y la esclavitud de los niños moriscos. Vélez Blanco (Almería), 1570-1580», en: Mélanges Louis Cardaillac, II.739-750.

[Análisis de los casos de niños moriscos encomendados "en administración" a cristianos viejos. Pese a su situación legal de teórica protección, la mayoría de las veces sus vidas eran las de auténticos esclavos, llegando a ser considerados "bienes" en transacciones comerciales. El autor muestra, a partir de casos diversos, cómo los cristianos "administradores" obviaban la legislación continuamente y llegaban a mantener en secreto la posesión de estos niños esclavos] L.B.P.

Aragón en la edad media, vol. X-XI, Zaragoza, Homenaje a la profesora emérita María Luisa Ledesma Rubio, 1993, 924 pp.

[Volumen doble, dedicado a la Profesora de Historia Medieval de la Universidad de Zaragoza. Se recensionan particularmente los trabajos más relacionados con mudéjares y moriscos] M.E.

ARANDA DONCEL, Juan, «Moriscos en tierras de Córdoba», Lamalif. AlAndalus, Almería, 5, 1992, 22-30.

[Artículo divulgativo, con abundantes notas bibliográficas, sobre mudéjares y moriscos cordobeses y sobre los granadinos inmigrados, tras la expulsión consecuencia de la guerra de Las Alpujarras (1568-1571)] M.E.

ARANDA DONCEL, Juan, «Los moriscos cordobeses y la cría de la seda. Aportación documental», en: Mélanges Louis Cardaillac, I.49-56.

[Contratos referentes a la cría de la seda en Córdoba en que intervienen moriscos como mano de obra especializada y que documentan su destacado papel en la industria sedera] L.B.P.

BARRIos Aguilera, Manuel, «Moriscos 'ydos a la sierra' en la guerra de las Alpujarras», en: Mélanges Louis Cardaillac, I.73-83. 
[Nómina de moriscos huidos a la sierra en la guerra de las Alpujarras a través del Apeo de las Gabias (1570), en el sur de la Vega de Granada. Consideraciones generales sobre las expropiaciones a "moriscos de paces" y perspectivas de estudio] L.B.P.

BAUMAN, Rolan, «Fiestas de la conquista en Andalucía y América», Lamalif. Al-Andalus, Almería, 5, 1992, 16-20.

[Artículo divulgativo sobre "Fiestas de Moros y Cristianos" en Las Alpujaras de Granada y "Fiestas de la Conquista" en Guatemala, basándose en la disertación doctoral del autor, titulada The Moors and Christians of Valor: Folklore and conflict in the Alpujarras, sobre la utilización política de esas fiestas históricas] M.E.

BIRRIEL SALCEDO, Margarita María, «Nuevos datos sobre el patrimonio confiscado a los moriscos: La costa de Granada», Chronica Nova, Granada, 21 (1993-1994):31-61.

BIRRIEL SALCEDO, Margarita María, «Notas sobre el matrimonio de los moriscos granadinos (1563)», en: Mélanges Louis Cardaillac, I.97-107.

[Rico estudio, a partir de las cartas de dote y arras granadinas, del matrimonio entre los moriscos de Granada. Desde la documentación, y con la metodología de la historiografía de la familia, la autora plantea unas primeras reflexiones e interrogantes sobre las circunstancias matrimoniales moriscas que amplían el campo de estudio] L.B.P.

BLASCO MARTíneZ, Asunción, «Notarios mudéjares de Aragón (siglos XIVXV)», Aragón en la edad media, vol. X-XI, Zaragoza, Homenaje a la profesora emérita María Luisa Ledesma Rubio, 1993, 109-133.

BOUZINEB, Husayn

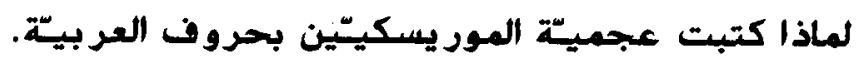

en: Ahmed-Chouqui Binebine (coord.), Le manuscrit arabe et la Codicologie, Rabat, 1994, pp. 99-112.

[«Por qué escribieron los moriscos la lengua no-árabe con letras árabes»].

BRAVO CARO, Juan Jesús, «Movimientos migratorios en Andalucía Oriental», en: Mélanges Louis Cardaillac, I.121-131.

[Estudio de la migración forzosa morisca a raíz de la Guerra de las Alpujarras y la inmigración de cristianos viejos a las comarcas de Andalucía oriental. Análisis de 
los mecanismos de deportaciones e inmigraciones. El autor señala la cautela que ha de tener el investigador a la hora de medir las consecuencias de la expulsión en las diferentes comarcas andaluzas] L.B.P.

BUNES IBARRA, Miguel Angel de, «La evolución de la polémica anti-islámica en los teólogos españoles del primer renacimiento», en: Horacio SANTIAGOOTERo (ed.), Diálogo filosófico-religioso entre cristianismo, judaísmo e islamismo durante la Edad Media en la Península Ibérica. Actes du Colloque International de San Lorenzo de El Escorial 23-26 juin 1991, Brepols, Société Internationale pour l'Étude de la Philosophie Médiévale, 1994, pp. 399-418.

[Estudio de los tratados de polémica españoles en los siglos XVI y XVII, que adquieren una dimensión especial frente a los europeos por su "familiaridad" con la comunidad islámica, lo que hace que deriven de la verdadera discusión teológica a manuales para el adoctrinamiento] L.B.P.

CABrillana CiÉZAR, Nicolás, Moriscos y cristianos en Yunquera (Málaga), Málaga, Arguval, 1994.

CABRILlANA CiÉZAR, Nicolás, «El problema morisco en la correspondencia del cardenal Espinosa», en: Mélanges Louis Cardaillac, I.133-143.

[Análisis de las referencias a la cuestión morisca en la correspondencia del cardenal Diego de Espinosa, presidente del Consejo de Estado y del Tribunal Supremo de la Inquisición, y representante de la línea dura para con los moriscos. Interesantes noticias sobre la guerra de Granada y sobre los moriscos que se quedaron] L.B.P.

CARDAILlAC, Louis, «El problema morisco y el descuaje del Islam peninsular», en Juan Bta. VILAR, Murcia frontera demográfica en el sur de Europa (I y II Jornadas de Inmigración magrebi, marzo 1993 - mayo 1994), Universidad de Murcia, Murcia, 1994, $176 \mathrm{pp}$.

[Conferencia con reflexiones generales y muy equilibradas sobre el tema] M.E.

CARdaIllac, Yvette, La magie en Espagne. Morisques et vieux chrétiens, XVjème et XVII ème siècles, Bordeaux, Université Michel Montaigne (Bordeaux III), 1994 [Tesis doctoral inédita].

CARDAILlaC, Yvette, «Le héros, maître du pouvoir magique: Salomon», en: Mélanges Louis Cardaillac, I.145-159.

[Análisis del papel de Salomón como poseedor de poderes sobrenaturales a través de tres mss. aljamiados. Consideraciones sobre el personaje en el islam y cómo estas características se proyectan también en los moriscos a través de las leyendas aljamiadas recogidas] L.B.P. 
CARMONA, Alfonso, "Los nuevos mudéjares: la shari'a y los musulmanes en sociedades no-islámicas», Comunidades islámicas en Europa (M. Abumalham ed.), Madrid, 1995, 49-59.

[Comparación amplia de situaciones, entre mudéjares de estatuto religioso reconocido en las sociedades hispánicas medievales y musulmanes actuales viviendo en las sociedades europeas. Reflexiones sobre posibles conflictos jurídicos y referencias a textos islámicos de legislación mudéjar del siglo XVI] M.E.

CARRASCO URGOITI, María Soledad, «Experiencia y fabulación en las Guerras Civiles de Granada de Ginés Pérez de Hita», Miscelánea de Estudios Arabes y Hebraicos, Granada, XLII-XLIII (1993-1994):49-72.

Carrasco Urgoiti, María Soledad, «Los moriscos en el pensamiento de Caro Baroja", Cuadernos Hispanoamericanos, 533-534 (1994):217-226.

CASTILlo FERNÁNDEZ, Javier, «Arrendamientos de bienes confiscados a moriscos en Baza y su tierra (1571-1616)», Chronica Nova, Granada, 21 (19931994):63-98.

CASTILlo FERNÁNDEZ, Javier, «'Hidalgos moriscos': Ficción histórica y realidad social. El ejemplo del linaje Enríquez Meclín de la tierra de Baza (siglos XV-XVIII)», en: Mélanges Louis Cardaillac, I.161-180.

[A través del ejemplo concreto de una de ellas el autor estudia cómo diversas familias moriscas se decían descendientes de un convertido voluntario antes de 1500 para obtener así grado de hidalguía. Mediante un proceso de endogamia y recurriendo incluso a la falsificación el linaje Enríquez Meclín mantuvo este propósito en diversos lugares durante tres siglos. El Apéndice II ha sido eliminado por los editores] L.B.P.

CERVERA FrAS, María José, «El nombre propio árabe medieval. Sus elementos, forma y significado», Aragón en la Edad Media, Zaragoza, IX, 1991, 225-240.

[Estudio general, documentado, pero sólo con fuentes árabes, no con ejemplos de la sociedad hispánica, de mudéjares o de moriscos] M.E.

Cervera Fras, María José, «Descripción de los manuscritos mudéjares de Calanda (Teruel)», Aragón en la Edad Media, vol. X-XI, Zaragoza, Homenaje a la profesora emérita María Luisa Ledesma Rubio, 1993, 165-188.

CHÉRIF, Mohamed-Hédi, «L'impact de la chute de Grenade sur le Maghreb entre la fin du XVe et le XVIII ${ }^{e}$ siècles», en: Fatma HADDAD-CHAMAKH - Alia 
BACCAR-BOURMAZ (eds.), L'écho de la prise de Grenade dans la culture européenne aux $X V I^{\mathrm{e}}$ et $X V I I^{\mathrm{e}}$ siècles, Tunis, Cérès Editions - Ministère de l'Education et des Sciences, 1994, pp. 17-23.

CORDENTE MARTÍNEZ, Heliodoro, La morisca Beatriz de Padilla (novela histórica), Madrid, Libertarias/Prodhufi, 1994, 347 pp., 30x13 cm.

[Relato novelado bastante verosímil, basado en 29 expedientes inquisitoriales (conservados en el Archivo Diocesano de Cuenca y que se reproducen y transcriben en parte, pp. 211-347), sobre la vida y ambiente social de la morisca de Arcos de Medinaceli (ahora Arcos de Jalón), condenada a muerte en Cuenca en 1598] M.E.

CORRIENTE CÓRDOBA, Federico - BOUZINEB, Hossain, Recopilación de refranes andalusíes de Alonso del Castillo, Zaragoza, Universidad de Zaragoza (Area de Estudios Arabes e Islámicos, 3), 1994, 242 pp.

[Edición del ms. 7453 de la Biblioteca Nacional de Madrid, que contiene una recopilación de refranes en árabe andalusí (más notas en castellano, latín y "en un árabe que intenta ser clásico") debida al morisco granadino Alonso del Castillo. Transcripción paleográfica y fonémica, más traducción anotada del texto original. Estudio lingüístico y ordenación del léxico estándar y andalusí] L.B.P.

CORTÉS PEÑA, Antonio Luis, «Treinta años de estudios sobre moriscos en revistas andaluzas (1962-1992)», en: Mélanges Louis Cardaillac, I.181-202.

[Aportación historiográfica sobre las líneas de estudio acerca de los moriscos en las revistas andaluzas en treinta años. El autor comenta, a veces con tono crítico, las aportaciones realizadas, sugiriendo también perspectivas de estudio. Los editores han eliminado el indispensable apéndice bibliográfico] L.B.P.

CROS, Edmond, «Narcissisme et discours identitaire dans la nouvelle L'Abencerrage», en: Mélanges Louis Cardaillac, I.203-208.

[Se establece un serie de puntos de reflexión para un análisis del discurso del Abencerraje como "discours identitaire", respuesta a una situación socio-histórica vivida como amenazante y que puede dar lugar a una estructura literaria narcisista y simbólica] L.B.P.

DACHRAOUI, Farhat, "A propos de la réalité culturelle des morisques en Tunisie", en: Fatma HADDAD-CHAMAKH - Alia BACCAR-BOuRMAZ (eds.), L'écho de la prise de Grenade dans la culture européenne aux XVI et XVII siècles, Tunis, Cérès Editions - Ministère de l'Education et des Sciences, 1994, pp. 57-63.

«Debat: a propòsit de l'obra de Pierre Guichard», Jueus, Conversos $i$ Cristians. Mons en contacte, Revista d'Història Medieval, Valencia, vol. 4, 1993, 229-260. 
[Presentación de la obra del medievalista francés, especialista en historia árabe valenciana, con ocasión de la publicación de su tesis doctoral Les Musulmans de Valence et la Reconquête (XIe-XIIIe siècles), Institut Français de Damas, Damasco, 2 vols., 1990 y 1991, por tres investigadores noveles del Departamento de Historia Medieval de la Universidad de Valencia. La presentación, asistemática y fragmentaria, de la obra del historiador francés (entre la hagiografía y la crítica) ni hace justicia a la seriedad de su aportación documental y su metodología para utilizarla, ni comprende los puntos esenciales de sus hipótesis de trabajo. Los subtítulos de los tres apartados indican bien lo esquemático de los planteamientos: "Producció, reproducció i colonització. Uns comentaris a propòsit de l'obra..." (J. Torró), "Ensayo de ideología" (G. Navarro - D. Igual), "Al-Andalus, Sociedad tributaria de frontera" (L. P. Martínez). Pierre Guichard se merecía -se merece aún- un debate a varias voces mucho más serio] M.E.

DEDIEU, Jean-Pierre, «L'Inquisition face à l'Islam», en: Granadas 1492. Histoire $\mathcal{E}$ Représentations, Toulouse, Amam, 1993, pp. 51-60 [Reedición ampliada en Mélanges Louis Cardaillac, I.209-220].

[Planteamientos generales en torno a la acción de la Inquisición con los moriscos situadas en un contexto social e histórico. Especificidad del problema morisco dentro de la acción general de la Inquisición] L.B.P.

DÍAZ DE RÁBAGO HERNÁNDEZ, Carmen, «Alimentación y religión en una morería valenciana bajomedieval: Castelló de La Plana», Millars. Espai i Història, Castelló de la Plana, XV, 1992, 99-109.

[Estudio documentado sobre prácticas religiosas musulmanas, judías y cristianas, en temas alimenticios] M.E.

DÍAZ DE RÁBAGO HERNÁNDEZ, Carmen, «Introducción al estudio de la aljama musulmana de Xivert durante la Edad Media», $3^{a s}$. Jornadas de Historia, Arte y Tradiciones Populares del Maestrazgo, Castellón, 1993, 63-72.

[Recopilación razonada de datos documentados, desde época árabe a la expulsión de los moriscos, señalando su importancia arqueológica] M.E.

DOMÍNGUEZ ORTIZ, Antonio, «Caro Baroja y los moriscos granadinos», Cuadernos Hispanoamericanos, 533-534 (1994):227-235.

L'écho de la prise de Grenade dans la culture européenne aux XVIe et XVIIe siècles.Edit. por Fatma HADDAD-CHAMAKH y Alia BACCAR-BOURNAZ.- Ministère de l'Éducation et des Sciences - Cérès Editions - Tunis, 1994.- 410 p. $(24 \times 16 \mathrm{~cm})$.

[Estudios reunidos en un volumen de Actas de un coloquio celebrado en Túnez y organizado por las profesoras Haddad-Chamakh y Baccar-Bournaz, de los Departamentos de Filosofía y de Francés de la Facultad de Letras, respectivamente. 
Los títulos de las colaboraciones muestran el enfoque predominantemente culturalista y pluridisciplinar del encuentro: "Le Maghreb au XVIIe siècle" (M.H.CHERIF), "L'Europe politique avant et après la chute de Grenade" (F. LEBRUN), "La refondation de l'État du Maghreb central au XVIe siècle. Les fondements internes et externes" (T. CHENTOUF), "Les effets de la chute de Grenade sur le Maroc: situation politique et sociale" (M. RAZOUK), "Morisques à Tunis au XVIle siècle" (F. DACHRAOUI), "Le rôle des Morisques dans la transformation du milieu rural de la Tunisie du XVIle siècle" (M. TURKI), "Survie grenadine à travers le costume féminin et les recettes culinaires, en Tunisie, au XVIIe siècle" (F. HARZALLAH), "Analyse, à valeur documentaire, d'une 'Kassida' morisque dédiée à Bajazet, sultan de Constantinople" (J. CHEIKHA), "Grenade et le sens d'une histoire: essai d'interprétation" (A. JDEY), "La prise de Grenade, sujet d'épopées et de romans. Épopées italiennes, romans français" (D. DALLA VALLE), "Le mythe de Saladin dans la littérature médiévale" (F. BERRIOT), "Othello ou l'image du Maure dans la tragédie élisabéthaine" (R. DARRAGE), "La chute de Grenade dans la littérature anglaise. Un exemple du XVIIe siècle: Almanzor et Almahide ou la Conquête de Grenade par les Espagnols de John Dryden" (M. RADDEDI), "L'ambitieuse grenadine ou la quête d'une impossible reconnaissance" (M. R. RAHMOUNI), "De l'image et des influences artistiques et littéraires de Grenade dans la poésie tunisienne (XVIe-XVIIe siècles)" (R. MARZOUKI), "Le mythe de Grenade dans la fiction narrative française du XVIIe siècle: une tentative d'inventaire" (A. BACCAR-BOURNAZ), "Grenade dans le Tolédan: fiction et histoire" (A. MOLINIE), "Cathérine Bernard et la tradition hispano-mauresque" (S. GUELLOUZ), "L'image du 'philosophe' arabe dans la chrétienté latine et les essais d'approche irénique du XIIe au XVe siècles" (M. de CONDILLAC), "Mise en scène du 'Château' dans le Livre des demeures de Sainte Thérèse d'Avila: une image de I'Islam dans la mystique espagnole?" (M. ALLENDE SALAZAR), "L'image de l'Islam chez les Protestants à la fin du XVIe siècle" (P.-F. MOREAU), "Images de l'autre monde: L'Islam dans la pensée italienne de la Renaissance" (P. CRISTOFOLINI), "Spinoza et Maïmonide" (A. CHENNOUFI), "Écho du récit du PHILOSOPHE AUTODIDACTE d'Ibn Thofail dans la culture européenne du XVIle siècle" (F. HADDAD-CHAMAKH), "Ibn Thofail et Spinosa, une rencontre en exil" (J. D. SÁNCHEZ ESTOP), "Ibn Bajja (Avempace) et Galilée. Transformation de la science et devenir de la pensée" (H. BEN JABALLAH), "Spinoza et Ibn Bajja" (S. MOSBAH), "Les conséquences idéologiques de la prise de Constantinople et de la prise de Grenade en Espagne aux XVe et XVIe siècles" (M. A. BUNES IBARRA), "La politique d'Isabelle la Catholique à l'égard des juifs et des musulmans" (S. HAYEK), "L'État espagnol et le refus de l'Autre" (B. VINCENT), "Impact de la musique grenadine sur la musique européenne au XVIe siècle" (M. GUETTAT), "La Moresca et les origines de l'exotisme musical en Europe au XVIle siècle" (T. BETZWIESER), "Chronique d'un royaume de taifa: la mémoire de Grenade à la veille du second siège de Vienne (l'opéra équestre du Roi Soleil)" (F. KARRO), "Apport maghrébin à la musique andalouse: le cas de la Tunisie" (J. AZZOUNA), "Iconographie de Grenade aux XVIe et XVIIe siècles" (M. KHEMIRI). Prólogo de M. de Candillac, presentación de las editoras y post-face de B. Vincent. Particular interés para los estudios sobre mudéjares y moriscos, especialmente en sus exilios en el Mágreb, en los trabajos de Chérif, Razouk, Dachraoui, Turki, Harzallah, Cheikh, Jdey, Marzouki, Azzouno, Khemiri] M.E. 
EsPinAR Moreno, Manuel - QUESADA GómEZ, J.J., «Las aguas de la Acequia Alta o de Mecina (Cogollos de Guadix). Los pleitos desde los siglos XII al XVIII. Algunas notas para su estudio», Miscelánea de Estudios Arabes y Hebraicos, Granada, XLII-XLIII, 1 (1993-1994):81-95.

ESPINAR MORENO, Manuel, «Ventas de aguas y enfrentamientos entre los vecinos de los barrios de la Alcazaba y el Albaicín en época morisca», en: Mélanges Louis Cardaillac, I.253-291.

[Detallado estudio sobre las ventas de agua en la Granada morisca, con la consideración de diversos pleitos mantenidos entre vecinos, moriscos y cristianos, y los poseedores de las licencias para la venta. Apéndices documentales] L.B.P.

Ferrer Mallol, María Teresa, "La capitulación de Borja en 1122», Aragón en la Edad Media, vol. X-XI, Zaragoza, Homenaje a la profesora emérita María Luisa Ledesma Rubio, 1993, 269-280.

Ferrer I MALlol, María Teresa, «La moreria de Xàtiva (segles XIV-XV)», Xàtiva. Els Borja. Una projecció europea, n 1, ed. Museu de 1'Almodí, Xàtiva, 1994, 189-200.

[Presentación anotada y documentada de la aljama de Xàtiva, con lista de sus autoridades y ubicación de su barrio. Ilustraciones de objetos y lugares de la Xàtiva islámica] M.E.

FONTENLA BALLESTA, Salvador, "Almirez hispanomorisco procedente de Inox (Almería)", Boletín de la Asociación Española de Orientalistas, Madrid, XXX, 1994, 299-300.

[Pieza de bronce, de tres kilos de peso, que fue depositada en el Museo Arqueológico de Lorca, con fragmentos de cerámica y monedas de la época de los Reyes Católicos encontrados en su alrededor. Fechable de época musulmana tardía. Dos fotos] M.E.

FRAYSSINHES, Sandrine, «Aragón y Túnez: Un parentesco arquitectónico. Las aportaciones moriscas», en: Mélanges Louis Cardaillac, I.293-302.

[Repaso por diversos elementos arquitectónicos tunecinos de construcción morisca y sus relaciones y parentesco con la arquitectura mudéjar aragonesa. Sorprende la ausencia en la bibliografía de los trabajos de A. Gafsi-Slama] L.B.P.

AL-QAFSî (EL-GAFSI), Abdel-Hakim

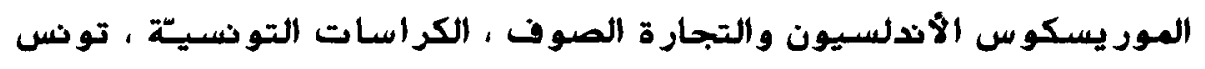

$155-156,1991,53-85$. 
[«Los moriscos andalusíes y el comercio de la lana» en Cuadernos tunecinos. Estudio del papel de la minoría andalusí en la regencia de Tunicia, descendientes de los moriscos expulsados de España, en el comercio de la lana (siglos XVII-XIX). Analiza su irrelevancia, según la documentación actualmente conocida, a pesar del peso que tenían los andalusíes en la fabricación del "gorro tunecino" o chechía, hecho de lana, principal exportación del país] M.E.

AL-QAFSî (EL GAFSI), Abdel-Hakim,

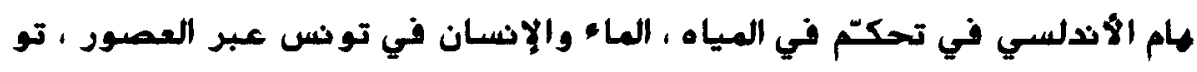

$1993,34-45$.

[«Participación andalusí en el reparto de las aguas» en El agua y el hombre en Tunicia a través de los siglos. Estudio documentado de las obras hidráulicas (fuentes, presas, norias...) de los moriscos y sus descendientes instalados en el norte de Tunicia] M.E.

GAFSI, Abdel-Hakim, «Une famille de monétaires sous les Husseinites: les Kastalli», Monnaies Tunisiennes depuis l'époque punique jusqu'à nos jours, Tunis, Banque Centrale de Tunisie, 1993, 23-40.

[Familia de moriscos o andalusíes descendientes de los expulsados del siglo XVII, poseedores de importantes bases económicas inmobiliarias, urbanas y rurales, ocupan cargos políticos y económicos, especialmente en la ceca tunecina, hasta el Protectorado francés (1881)] M.E.

GAFSI, Abdel-Hakim, «Découverte d'une conduite d'eau dans un village morisco-andalous en Tunisie: Ghal El Melh (Porto Farina) (Note préliminaire)», Actes du Ve Symposium International d'Études morisques. Le Ve Centenaire de la chute de Grenade 1492-1992, CEROMDI, Zaghouan (Tunicia), 1993, 283-290.

[En uno de los lugares rurales y costeros donde se instalaron los moriscos expulsados de España en el siglo XVII] M.E.

GAFSI-SLAMA, Abdel-Hakim, «Un ejemplo de ambivalencia artística y lingüística: el sbil de Youssef Dey (1631) en Bizerta, en Tunicia», Arab Historical Review for Ottoman Studies, Zaghouan, 9-10 (1994):317-322 (en árabe), 219 (resumen en francés).

GAFSI-SLAMA, Abdel-Hakim, «Aperçu sur l'ancien 'palais' de Mustafa de Cárdenas à Grombalia», en: Mélanges Louis Cardaillac, I.303-318.

[Descripción de los restos del palacio del jefe de la comunidad morisca de Túnez. Noticias sobre su vida y sobre la ciudad de Grombalia. Fotografías. Planos] L.B.P. 
GALMÉs dE FUENTES, Alvaro, «Los Moriscos», Lamalif. Al-Andalus, Almería, 5, 1992, 6-15.

[Artículo de presentación general, con notas y antología de textos] M.E.

GALMÉS DE FUENTES, Alvaro, «La literatura aljamiada nos revela el secreto: ant. esp. consograr 'emparentar por afinidad o por razón de matrimonio'», Boletín de la Real Academia Española, Madrid, LXXIV (1994):7-14.

[Nota acerca del significado del antiguo español consograr 'emparentar por razón de matrimonio', presente en un ms. aljamiado y procedente del árabe ahara 'establecer lazos de parentesco con el suegro o yerno': posee no sólo la idea de desposar sino la de adscripción a un grupo social. Este significado confirmado obliga a corregir las lecturas del término en el Poema de Mio Cid (vv. 1996 y 3356) y en el ms. de París del Libro de Aleixandre] L.B.P.

GARAUDY, Roger, «Por un diálogo entre culturas», Lamalif. Al-Andalus, Almería, 5, 1992, 32-41.

[Comparación general entre destrucción de la cultura amerindia y de la cultura hispano-islámica, en la España del XV-XVII] M.E.

García ARENAL, Mercedes, «Vidas ejemplares: Sa`îd Faraŷ Al-Dugali, un granadino en Marruecos (m. 987/1579)», Lamalif. Al-Andalus, Almería, 5, 1992, 62-74.

[Reproducción de artículo de investigación publicado en 1988, con abundantes notas (Actas del Congreso "Relaciones de la Peninsula Ibérica con el Magreb (siglos XIIIXVI)", eds. M. J. Viguera - M. GarCía-Arenal, Madrid, 1988)] M.E.

GARCíA MARCO, Francisco Javier, «Tipología documental e investigación histórica: las actas notariales como reflejo de la evolución de la sociedad aragonesa en la Edad Media», Aragón en la Edad Media, Zaragoza, IX, 1991, 31-53.

[Estudio metodológico, con incidencia en los mudéjares que aparecen en esta documentación] M.E.

GARCíA PEDRAZA, Amalia, «La asimilación del morisco Don Gonzalo Fernández El Zegrí: Edición y análisis de su testamento», Al-Qanțara, Madrid, XVI, 1 (1995):39-58.

GARCíA PEDRAZA, Amalia, «El morisco ante la muerte. Algunas reflexiones sobre los testamentos otorgados por los moriscos granadinos (1500-1526)», en: Mélanges Louis Cardaillac, I.337-352.

[Estudio de los testamentos de los moriscos granadinos y de las perspectivas mentales y religiosas que de ellos se derivan. Destaca la autora ciertos rasgos diferen- 
ciales respecto a los testamentos de los cristianos viejos que ilustran un lento y dudoso proceso de asimilación. Rico estudio que abre novedosas expectativas] L.B.P.

GARCíA LATORRE, Juan, «Los moriscos de la Sierra de Filabres (Almería)», en: Mélanges Louis Cardaillac, I.329-336.

[Panorámica general sobre la sierra de Filabres y los moriscos que allí habitaban, a partir de los libros de Apeo y Repartimiento. Comunidad morisca dedicada especialmente a la ganadería] L.B.P.

GonZÁlez Rodríguez, Alberto, Hornachos, enclave morisco. Peculiaridades de una población distinta, Mérida, Asamblea de Extremadura. Publicaciones y Editora Regional de Extremadura, 1990, 181 pp., 12 ilustr., $25 \times 18 \mathrm{~cm}$.

[Estudio de Hornachos (Badajoz), especialmente desde el punto de vista urbanístico y literario, sin olvidar a los moriscos] M.E.

GOZALBES BUSTO, Guillermo, «Antroponimia y sociología morisca en Argel (Datos para su estudio)», en: Mélanges Louis Cardaillac, I.353-380.

[Líneas generales acerca del asentamiento morisco en Argel, con vaciado de fuentes sobre antroponimia y oficios. Listado de apellidos hispánicos en Argel, comparándolos con los recogidos anteriormente en Tetuán] L.B.P.

Granadas. Histoire et représentations, AMAM (Université de Toulouse - Le Mirail), Toulouse, 1993, 223 pp. (24x17 pp.).

[Textos presentados en un coloquio organizado por la asociación universitaria "Analyses - Monde Arabe et Méditerranée", que anima y dirige el profesor Edgard Weber, con el tema genérico "Granadas 1492-1992, du royaume de Grenade à l'avenir du monde méditerranéen", el 11 y 12 de diciembre de 1992. Los títulos de las aportaciones - reflexiones y estudios - muestran claramente los objetivos y la riqueza de este volumen de "andalusistas" francófonos, franceses y magrebíes: "À propos de Grenade" (E. WEBER), "Les taifas et la Reconquête: quelques éléments d'analyse" ( $F$. CLÉMENT), "Le concept d'État et de pouvoir en Andalus: les raisons d'un éclatement et d'une disparition" (P. GUICHARD), "Les bases fiscales du pouvoir au Magrib al-aqsà et en Andalus (XIe et XIIe siècle)" (V. LAGARDĖRE), "La fonction de sayh sous les Mérinides" (S.A. KHANEBOUBI), "L'Inquisition face à l'Islam" (J.-P. DEDIEU), "Al-Hagari ou la production d'un discours d'exclusion" (A. GHOUIRGA$\mathrm{TE}$ ), "Sources arabes de la pensée européenne (XIIe-XVIe siècles)" (A. de LIBÉRA), "1492-1992: le déplacement d'ouest en est de la confrontation Nord-Sud en Méditerranée" (R. HEACOCK), "L'école musicale d'al-Andalus à travers l'oeuvre de Ziryâb" (M. GUETTAT), "Les troubadours et la musique arabe" (G. LE VOT), "La chute de Grenade dans la littérature arabe" (N. ABI-RACHED), "L'Andalus dans l'imaginaire arabo-musulman contemporain (exemple du cinéma tunisien)" (O. YOUSSEF), "La Reconquête: un projet dynastique" (S. HAYEK), "Intégration, exclusion, expulsion, selon le droit et la réalité de l'islam" (F. DACHRAOUI), "1492-1992 ou le bon 
usage de 1'histoire" (J. CHESNAUX). Resúmenes en castellano, inglés y árabe. Aunque todo el volumen tiene relación con mudéjares y moriscos, evidentemente, hay que destacar los capítulos de Weber, Dedieu, Ghouirgate, Abi-Rached y Dachraoui] M.E.

Grima Cervantes, Juan, Almería y el Reino de Granada en los inicios de la modernidad (s. XV-XVI). Compendio de Estudios, prólogo de Bernard Vincent, Arráez Editores (Colección Investigación, I), Almería, 1993, 349 pp. , $21^{\prime} 5 \times 15^{\prime} 5 \mathrm{~cm}$.

[Conjunto de 13 estudios centrados en la historia de la región de Almería en el período principal de la transformación de la sociedad musulmana en cristiana (14881505). Prólogo de Bernard Vincent que subraya las dimensiones de la investigación y edición actuales sobre este período. Documentación generalmente inédita. Temas importantes sobre conversiones de nobles granadinos, sobre rebelión mudéjar de 15001501, sobre pactos diversos, ataques marítimos, pesca almeriense, etc. Indices de topónimos y antropónimos] M.E.

HAÏDARA, Ismael Diadié, El bajá Yawdar y la conquista saadí del Songhay (15911599), Almería (Instituto de Estudios Almerienses) y Cuevas del Almanzora (Ayuntamiento), 1993, 178 pp., 24x17 cm.

[Estudio sobre este morisco natural de Cuevas, general marroquí que encabezó una expedición al río Níger (especialmente el Songhay, capital Tumbuktú), con moriscos y otras tropas, bajo la dinastía marroquí de los Saadíes] M.E.

Harvey, Leonard Patrick, «Menéndez Pidal and Aljamiado Literature», Journal of Hispanic Research, London, 2 (1993-1994):133-134.

HAYEK, Simon, «El morisco jesuita Ignacio de las Casas», en: Mélanges Louis Cardaillac, I.387-394.

[Nota sobre Ignacio de las Casas construida sobre trabajos anteriores de otros autores] L.B.P.

HiMd, Hasna, Bibliographie commentée des Morisques (1991-1994), Montpellier, Université Paul Valéry, 1994 [Mémoire de maîtrise d'espagnol].

Historia Medieval. Anales de la Universidad de Alicante, n 9, 1992-1993.

[El n ${ }^{\circ} 9$ de los Anales de la Universidad de Alicante, dirigidos por el Departamento de Historia Medieval correspondiente a 1992-1993, y publicado por el Secretariado de Publicaciones de la Universidad de Alicante en 1995, rinde homenaje al Prof. Juan Manuel del Estal con motivo de su jubilación académica. D. Juan Manuel del Estal centró sus líneas de investigación en las taifas de Valencia y Murcia; la dominación valenciana de las tierras alicantinas adjudicadas a $D$. Alfonso de Castilla por el 
Tratado de Almizra, y a la hegemonía aragonesa en el reino de Murcia desde la conquista por Jaime II hasta el 1305.

Los artículos en los que se recogen datos sobre el período mudejar o morisco son los de: M. de Epalza en "Notas sobre Benimagrell, antropónimo árabe-latino del siglo XIII y topónimo actual de Alicante", donde estudia el origen de la familia de los Ibn Magrel. F. Franco Sánchez, al tratar de los Sidi Bono en su artículo "Cocentaina en el período islámico: poblamiento y geopolítica", se refiere al del período mudéjar valenciano de esta familia. J. Hinojosa Montalvo en "Aproximación a la ganadería alicantina en la Edad Media", hace mención a la densa población mudéjar del valle de Elda, a las revueltas mudéjares de finales del siglo XIII en Cocentaina y al bandolerismo mudéjar (s. XIII-XIV) y tiene un apartado dedicado a "El ganado de mudéjares y judíos". $\mathrm{M}^{\mathrm{a}}$ Teresa Ferrer i Mallol "El justícia a les viles de la governació d'Oriola (s. XIV)", analiza la reorganización de los cargos públicos de la ciudad de Orihuela tras la conquista del reino de Murcia por Jaime II. En el artículo de P. J. Pla Alberola "La carta puebla de Señera en 1445" se menciona los censatarios mudéjares que en ella aparecen, se habla de los mudéjares de Játiva y se hacen alusiones a las consecuencias que en la zona de Benemejís y Señera tuvo la expulsión de los moriscos. Y, finalmente, en el artículo "Piezas cerámicas emblemáticas del señorío de los Corella en el Valle de Elda (siglo XV) "A. M. Poveda Navarro se refiere a la tensión social en el valle de Elda, fruto de la opresión de la minoría cristiana sobre la mayoría musulmana] E.L.G.

Iberia and the Mediterranean World of the Middle Ages. Studies in honour of Robert I. Burns S.J., vol. I : Proceedings from Kalamazoo, edit. Larry J. SIMON, E. J. Brill, Leiden, 1995, XXVI-373 pp., 25x16'6 cm.

[Estudios en honor del jesuita medievalista estadounidense Burns, especializado en la historia de la Corona de Aragón, especialmente en el siglo XIII valenciano. El primer volumen reúne los trabajos del encuentro de Kalamazoo (Michigan, USA), tras la presentación del libro y del homenajeado por L. J. Simon: "Ramon Llull and the Compulsory Evangelization of Jews and Muslims" (M.D. JOHNSTON), "Christian Kalâm in Twelf-Century Mozarabic Apologetic in Spain". (T. E. BURMAN), "Sense of Mission: Arnau de Vilanova on the Conversion of Jews and Muslims" (J.A. BOLLWEG), "The Sources for Alfonso de Espina's Messianic Argument Against the Jews in the Fortalitium Fidei" (S. J. McMICHAEL), "Religious Change, Regionalism, and Royal Power in the Spain of Fernando and Isabel" (M. D. MEYERSON), "Pro exaltatione sanctae fidei catholicae": Mission and Crusade in the Writings of Ramon Llull" (P. D. BEATTIE), "Early Catalan Contacts with Byzantium" (S. B. BENSCH), "An Interdisciplinary and Comparative Approach to Northern Tuscan Ports in the Early and High Middle Ages" (S. O. BUSCH), "Loans, Land, and Jewish-Christian Relations in the Archdiocese of Toledo" (N. MELECHEN), "The Relationsship between Conquest and Settlement on the Aragonese Frontier of Alfonso I" (W. C. STALLS), "Means of Exchange: Islamic Coinage in Christian Spain, 1000-1200" (J. TODESCA), "Frederick II and the Muslims: The Making of an Historiographical Tradition" (J. M. POWELL), "Dominican Papalism ant the Arts in Fifth-Century Rome" (T. M. IZBICKI), "The Origins of Hospitallerims in Medieval Catalonia" (J. W. BRODMAN), "The 'Sainted Queen' and the 'Sin of Berenguela': Teresa Gil de Vidaure and Berenguela Alfonso in Documents of the Crown of Aragon, 1255-1272" (C. L. CHAMBERLIN), 
"A stemma codicum for Francesc Eiximenis' Dotzè del Crestià" (D. M. ROGERS), "The Struggle Against Poverty: Mendicant Life in Late Medieval Puigcerdà" (J. R. WEBSTER), "The Church and Slavery in Ramon Llull's Majorca" (L. S. SIMON). Indice onomástico y de materias. Para el estudio de mudéjares y moriscos interesan especialmente los trabajos de Johnston, Burman, Bollweg, Meyerson, Beattie, Stalls] M.E.

ISA SAOIR, Abd al-Hamid

$$
\text { الملكة ايزابيل الكاثوليكية ودور ها في اسقاط دولة الاسـلام في الاندلس }
$$

en: Mélanges Louis Cardaillac, II.97-131.

[«La reina Isabel la Católica y su papel en la caída del islam en al-Andalus». Presenta el período histórico que precedió a la reina Isabel para después pasar a tratar de su vida y de sus convicciones políticas en relación a Granada. Comenta toda la fase de asedio a Granada, la entrega de la ciudad y el tratamiento que los reyes Católicos dieron a los moriscos] E.L.G.

Justel CAlabozo, Braulio, «El manuscrito aljamiado de El Escorial n ${ }^{\circ} 1880$ », Lamalif. Al-Andalus, Almería, 5, 1992, 95-98.

[Presentación del único manuscrito aljamiado de la Biblioteca del Monasterio de San Lorenzo del Escorial, escrito por el imam de la villa de Agreda (Soria), en 976/1569] M.E.

LANDA, R.G., «Le rôle économique et social des morisques en Espagne», en: Mélanges Louis Cardaillac, 1.395-409.

[Consideraciones generales acerca de la importancia económica de los moriscos en la sociedad española y del impacto de la expulsión en las tierras peninsulares, así como en el exilio] L.B.P.

LAVAdo PARAdinas, Pedro José, «Restos mudéjares en la red viaria del Madrid medieval», Caminos y caminantes por las tierras del Madrid medieval (Cristina SEgura Graíño, ed.), 1994.

LEBLON, Bernard, «Moriscos y gitanos en la España de los siglos XVI y XVII», en: Mélanges Louis Cardaillac, I.421-430.

[Repaso a la historia de las confusiones entre moriscos y cristianos. El autor incide, aportando documentación, en la diferenciación de ambas comunidades, con muy pocas conexiones antre ambas, conexiones entre las que se descarta el cante flamenco] L.B.P.

LEDESMA RUBIO, María Luisa, «Marginación y violencia. Aportación al estudio de los mudéjares aragoneses», Aragón en la Edad Media, Zaragoza, IX, 1991, 203-224. 
[Aportaciones documentadas y reflexiones generales sobre la integración de los mudéjares en la sociedad aragonesa y sus relaciones con cristianos y judíos] M.E.

Ledesma Rubio, María Luisa, Cartas de población del reino de Aragón en los siglos medievales, Zaragoza, Institución Fernando el Católico, 1991, 543 pp., $24 \times 17 \mathrm{~cm}$.

[Introducción (pp. 7-22), edición (24-326) e índice onomástico (329-543, por Javier GARCÍA MARCO), de 247 documentos, fechados entre 1069 y 1451] M.E.

LIMĀM, Taoufik, Edición, estudio lingüístico y glosario del ms. morisco $n^{\circ} 6016$ B.N.M., Madrid, Universidad Complutense, 1995 [Tesis Doctoral Inédita].

LÓPEZ ANDRÉS, José, «Persistencia de los moriscos en el mundo gitano, una cuestión pendiente», Lamalif. Al-Andalus, Almería, 5, 1992, 56-60.

[Artículo divulgativo, con conclusiones meramente hipotéticas] M.E.

LÓPEZ-BARALT, Luce, «El conjuro mágico de Salomón a la Alhabiba», en: Mélanges Louis Cardaillac, I.431-443.

[Edición y estudio de un fragmento del ms. aljamiado T 26 de la Real Academia de la Historia acerca de las conjuras contra la genia Alhabiba, maléfica para los niños a punto de nacer. Estudio del personaje de Salomón como dominador de genios y de otros genios femeninos en el folklore musulmán. Reproducción facsímil del fragmento] L.B.P.

LÓPEZ-BARALT, Luce, «En busca de un profeta perdido. El viaje maravilloso de Buluquía a los confines del universo en una leyenda aljamiada del siglo XVI», Vuelta, México, 221 (abril 1995):20-25.

[Análisis de la leyenda contenida en el ms. Junta VIII sobre el viaje de un joven israelita, Buluquía, en busca del Profeta del islam, a quien ha visto anunciado en la Torá. Historia conservada en las Mil y una Noches, el autor morisco parece seguir sin embargo una versión cercana a las Qisas al-anbia' de Ta'alibi. Destaca, como contraste en el contexto de la literatura peninsular, su carácter maravilloso que acerca el relato a la literatura de mirabilia] L.B.P.

LÓPEZ DE COCA CASTAÑER, José Enrique, «La 'conversión general' en el obispado de Málaga (1500-1501)», Chronica Nova, Granada, 21 (1993-1994):191237.

López Elum, Pedro, La alquería islámica en Valencia. Estudio arqueológico de Bofilla. Siglos XI a XIV, Valencia, 1994, 357 pp, 180 fot., lám., plan. 
LóPEZ-MORILLAS, Consuelo, Textos aljamiados sobre la vida de Mahoma: el profeta de los moriscos. Edición y estudio, Consejo Superior de Investigaciones Científicas - Agencia Española de Cooperación Internacional (col. Fuentes arábigo-hispanas, 16), Madrid, 1994, 199 pp., 24x17 cm.

[Selección de textos en lengua hispana y escritura árabe (aquí transcritos en escritura latina) referentes a Mahoma, profeta del Islam. Una breve introducción histórico-religiosa. Estudio lingüístico. Edición modernizada de trece textos, con indicación de fuentes conocidas. Glosario de voces. Indices de nombres propios y frases y expresiones árabes. Bibliografía selecta] M.E.

LÓPEZ-MORILLAS, Consuelo, «Aljamiado and the Moriscos' Islamicization of Spanish», Perspectives on Arabic Linguistics VI (M. EID, V. CANTARINO y K. WALTERS eds.), John Benjamin Publishing Company, Amsterdam, 1994, 19-23.

[Presentación de elementos lingüísticos del español de los mudéjares y moriscos influidos por la lengua árabe de estos musulmanes hispanos (arabismos no traducidos, arabismos modificados por la morfología románica, calcos semánticos del árabe, etc.), con numerosos ejemplos] M.E.

LÓPEZ-MORILLAS, Consuelo, «Language and Identity in Late Spanish Islam», Hispanic Review, Philadelphia, 63, 2 (spring 1995):193-210.

[Estudio de la lengua de los moriscos como su seña de pertenencia al islam. Los moriscos realizan en los manuscritos aljamiados un proceso de semitización de su lengua romance, imbricando problemas religiosos y lingüísticos, como los ejemplos aducidos del Mancebo de Arévalo] L.B.P.

MAGNIER HENEY, Grace, «Román Ramírez: villain or victim? El perro de San Roque / no tiene rabo / porque Ramón Ramírez / se lo ha cortado», en: Mélanges Louis Cardaillac, I.449-455.

[Análisis de la figura del médico morisco Román Ramírez tal como es presentado en la obra Quien mal anda en mal acaba de Juan Ruiz de Alarcón comparado con las fuentes de su juicio inquisitorial (Caro Baroja, González Palencia...). La autora profundiza en la visión que la sociedad cristiana podía tener de los médicos moriscos y señala el nivel de prejuicios entre ambos grupos (representados en la obra de Ruiz de Alarcón), sólo superables por figuras racionalistas como Pedro de Valencia] L.B.P.

MAMI, Ridha, «Los milagros del profeta Mahoma en algunos manuscritos moriscos», en: Mélanges Louis Cardaillac, I.457-464.

[Recopilación, sin explicación, de algunos milagros del Profeta Mahoma recogidos en textos moriscos del exilio] L.B.P.

MARTíneZ, François, «Les enfants morisques de l'expulsion (1610-1621)», en: Mélanges Louis Cardaillac, II.499-539. 
[Detallado estudio, a partir de la documentación contemporánea pero también de estudios modernos, sobre la cuestión de la permanencia de los niños moriscos en el momento de la expulsión. Reflexiones acerca de los aspectos del problema, sobre todo la validez del bautismo y los colegios de evangelización (especialmente Valencia)] L.B.P.

MARTínEZ MARTÍNEZ, María, «Colaboracionismo castellano-aragonés ante la violencia mudéjar (1390)», Aragón en la Edad Media, vol. X-XI, Zaragoza, Homenaje a la profesora emérita María Luisa Ledesma Rubio, 1993, 589-602.

MARTÍNEZ RUIZ, Juan, "Ausencia de literatura aljamiada y conservación del hispano-árabe y de la entidad árabo-musulmana en la Granada morisca (siglo XVI)», Chronica Nova, Granada, 21 (1993-1994):405-425.

[La literatura aljamiada se desarrolló en Aragón y Castilla como resultado de la pérdida del árabe en estas regiones. Por contra, en Valencia y Granada se conservó el árabe, por lo que no existen en estas zonas producciones aljamiadas, toda vez que se ha demostrado que la "carta aljamiada granadina" es de procedencia aragonesa] L.B.P.

McClaIN, Michael, «Morisco Pioneers of the Old South», en: Mélanges Louis Cardaillac, II.541-548.

[Impresiones, sin base científica, acerca de posibles huellas moriscas en el sudeste de los Estados Unidos] L.B.P.

MEDINA MOlERA, Abderrahman, «Origen de la identidad y causa morisca», Lamalif. Al-Andalus, Almería, 5, 1992, 82-94.

[Disquisiciones islámicas sobre toda la Edad Media peninsular] M.E.

MOLÈnAT, Jean-Pierre, "Una famille de l'élite mudéjare de la Couronne de Castille: Les Xarafí de Tolède et d'Alcalá de Henares», en: Mélanges Louis Cardaillac, II. 765-772.

[Estudio de la familia toledana Xarafí, más tarde afincada en Alcalá de Henares, a partir de documentación de los siglos XIV y XV. Familia de la elite mudéjar, entre sus miembros atestigua el autor alfaquíes, médicos, repartidores, etc., destacando la figura de Abrahem Xarafi, nombrado alcalde mayor de las aljamas del reino en 1475. Rastreo en las fuentes árabes del apellido] L.B.P.

MONER, Michel, «Las falsificaciones de la historia de España», en: Pedro Laín ENTralgo - Luis Rosales - José Antonio Maravall (eds.), Homenaje a Julio Caro Baroja. Cuadernos Hispanoamericanos, 533-534 (1994):69-82.

Los Moriscos, número especial de la revista Lamalif. Al-Andalus, Almería, 5, dic. 1992,98 pp. 
[Volumen de divulgación abundantemente ilustrado, con prólogo del director de la revista Abd Al-Rahman Medina Molera, con artículos de A. Galmés de Fuentes, E. Bauman, R. Garaudy, M. J. Viguera Molins, J. López Andrés, M. García Arenal, M. A. Unan, A. Medina Molera, B. Justel Calabozo y breve apéndice "Apellidos moris$\cos ^{\prime \prime}$, que se recensionan separadamente] M.E.

Muñoz Buendía, A. - Díaz LóPez, J. P., «La producción agraria en la Almería morisca e ilustrada. Un estudio comparado a través de los diezmos», en: Mélanges Louis Cardaillac, II.549-562.

[Comparación de la producción agraria en los períodos 1559-62 y 1747-51 en la Tierra de Almería. Los autores llegan a la conclusión del perjuicio de la expulsión de los moriscos, pues a mitad del siglo XVIII la relación hombre-producción agraria (aceite, trigo, cebada, seda) es menor que en el siglo XVI] L.B.P.

NARVÁEZ, María Teresa, «El Mancebo de Arévalo, lector morisco de La Celestina», Bulletin of Hispanic Studies, LXXII (1995):255-272.

[Reedición mejorada de un importante artículo de 1990 en el cual la autora descubre inserto en la Tafsira del Mancebo de Arévalo un fragmento del prólogo de La Celestina de Fernando de Rojas. Estudio de la motivación de Rojas al traducir este mismo fragmento de Petrarca y visión de las perspectivas mentales del Mancebo al usar de esta cita sobre el mundo como contienda] L.B.P.

PORRAS ARBOLEDAS, Pedro A., «Fueros, privilegios y ordenanzas de la villa de Jódar. Cinco siglos de derecho municipal», Historia, Instituciones, Documentos, Sevilla, 21 (1994): 391-422. E.L.G.

[Menciona las relaciones de los cristianos con las minorías de moros y judíos]

Proyección histórica de España en sus tres culturas: Castilla y León, América y el Mediterráneo (Eufemio Lorenzo Sanz (coordinador), Junta de Castilla y León, Consejería de Cultura y Turismo, 3 vols. Valladolid, 1993, 675- -399 pp., $24 \times 17 \mathrm{~cm}$.

[Volúmenes con estudios de muy diversa temática. Tienen especial relación con mudéjares y moriscos:

$M^{a}$. Fátima CARRERA DE LA RED, «Arabes y Judíos en la documentación del monasterio de Sahagún», vol. I, 45-51 [además de mozárabes, a partir del $X$, aparecen nombres musulmanes, desde 964 al siglo XV, algunos de ellos de esclavos "moros y moras", y de la "aljama de moros" del pueblo de Sahagún (documentación de $1291,1319,1377 \ldots)]$.

Máximo DIAGO HERNANDO, «Mudéjares castellanos en la frontera de Aragón. El caso de Agreda», vol. I, 67-72 [documentación de fines del XV y de principios del $\mathrm{XVI}]$. 
Manuel GONZÁLEZ JIMÉNEZ, «El fracaso de la convivencia de moros y judíos en Andalucía», vol. I, 129-149 [síntesis, con bibliografía final].

Jesús LALINDE ABADÍA, «España en la encrucijada de la "Xaría", la "Torá" y el "Directum" ", vol. I, 165-210 [reabre discusión Castro y Sánchez Albornoz, insistiendo sobre la poca permeabilidad de los sistemas jurídicos musulmán y judío -por ser personales y no territoriales- y del cristiano excluyente de las otras "leyes"].

Joseph PÉREZ, «Mozárabes y mudéjares en la España medieval», vol. I, 239-249 [reflexiones sobre los paralelismos de esas comunidades].

Enrique SORIA MESA, «La integración de la élite nazarí en la nobleza granadina. Siglos XV al XVII», vol. I, 295-307 [económica y social; con referencias documentales diversas].

$M^{a}$. Antonia VARONA GARCÍA, «Judíos y Moros ante la justicia de los Reyes Católicos. Cartas Ejecutorias de la Real Chancillería de Valladolid (1476-1495)», vol. I, 337-368 [presentación de 116 docs.].

Bernard VINCENT, «Los moriscos y los idiomas árabe, castellano y catalán», vol. I, 369-378 [texto documentado, en francés].

GÓMEZ RENAU, Ma . del Mar, «La influencia del aljamiado en la prosa medieval castellana», vol. II, 83-

ALBARRACÍN NAVARRO, Joaquina, «El hijo de Iblîs (el demonio) Samhurûs Ibn Dahmurûs Al-Wati'a y la marca samhurûs en un manuscrito inédito árabe mudéjar de Ocaña (Toledo)», vol. III, 15-22 [Texto árabe original fotografiado y traducción al castellano, del libro Misceláneo de Salomón, descubierto en 1969. Presentación del texto y de su temática].

MARTÍNEZ RUIZ, Juan, «Onomástica femenina en la Granada morisca (año 1565)», vol. III, 131-142 [estudio, a partir de archivos notariales de la ciudad de Granada, conservados en el Archivo de la Alhambra] M.E.

RACHIDI, Fatima, "La presènce des Andalusis (Moriscos) dans l'Armée saadienne», en: Mélanges Louis Cardaillac, II.575-590.

[Visión general acerca del papel de los moriscos en el ejército marroquí, en especial sus relaciones con los sucesivos sultanes. Se detiene en la figura del granadino Dugali] L.B.P.

RIOSALIDO, Jesús, «Zéjeles madrileños en un Corán morisco», Boletín de la Asociación Española de Orientalistas, Madrid, XXX, 1994, 129-139.

[Presentación, sin notas, y traducción de unos textos poéticos en árabe que se encontraron en las tapas de un manuscrito magrebí de 1641, que el autor atribuye a moriscos. Lo de "madrileños" es por el lugar en el que se compró dicho texto en 1985. Presentación del manuscrito en vol. XXVIII (1992) del mismo Boletín de la A.E.O.] M.E. 
RoIG, Adrien, «Interpretation du Baile de los moriscos (1615)», en: Mélanges Louis Cardaillac, II.591-612.

[Edición y detenido estudio de este Baile de Vélez de Guevara, que se presenta como un valioso documento contemporáneo de la expulsión acerca de los moriscos valencianos, pues incide sobre su postura ante el decreto, aparte de recoger algunos rasgos cómicos asociados al morisco teatral. Ilustraciones] L.B.P.

RUBiera MATA, María Jesús, «La voz de las poetisas en al-Andalus y la problemática de la voz femenina literaria medieval», La voz del silencio, t. I : Fuentes directas para la historia de las mujeres (siglos VIII-XVII) (Cristina SEGURA GRAíñ editora), Madrid, Asociación Cultural “Al-Mudaina", 1992, 65-70.

[Problemática árabe oriental y europea, frente a la voz masculina, también en la sociedad mudéjar y morisca] M.E.

RUBiera MATA, María Jesús, «Los textos epigráficos de los palacios nazaríes (algo más que una escritura)», en: VV. AA., Arte islámico en Granada, Granada, Patronato de la Alhambra y Generalife, 1995, pp. 97-105.

[Penetrante estudio y análisis histórico, literario y estético de los textos epigráficos de los palacios nazaríes de la Alhambra. La autora hace notar que la primera lectura moderna de las inscripciones, la del morisco granadino Alonso del Castillo, no contiene "más que las inscripciones no estrictamente religiosas" por temor que las religiosas -incluido el famoso lema de los nazaríes- fueran suprimidas de los muros de la Alhambra] L.B.P.

SÁNCHEZ MAYRENA, Alfonso, «Socioeconomía de una población morisca. Ojén: finales del siglo XV y principios del XVI», 1490: En el umbral de la modernidad. El Mediterráneo europeo y las ciudades en el tránsito de los siglos XVXVI, Valencia, Generalitat Valenciana, 1994, vol. II, pp. 577-584.

SÁNCHEZ RAMOS, Valeriano, «El paisaje agrario de la taha de Berja en el siglo XVI», 1490: En el umbral de la modernidad. El Mediterráneo europeo y las ciudades en el tránsito de los siglos XV-XVI, Valencia, Generalitat Valenciana, 1994, vol. II, pp. 647-657.

SÁNCHEZ RAMOS, Valeriano, "Los moriscos que ganaron la guerra», en: Mélanges Louis Cardaillac, II.613-627.

[Diferenciación tripartita entre los grados de "colaboracionismo" de los moriscos granadinos: moriscos de Paces, los que intentaron sacar ventaja de la situación y los que abogaron por una convivencia pacífica y más justa, a la postre los más perjudicados] L.B.P. 
SANTANA PÉREZ, Juan Manuel, «Presencia morisca en las islas Canarias», en: Mélanges Louis Cardaillac, II.629-647.

[Presencia de "moriscos" (aquí cautivos musulmanes norteafricanos convertidos y sus descendientes) en Canarias y sus relaciones con las autoridades cristianas. Introducidos como esclavos en los siglos XVI-XVII, su utilidad les hace verse exentos de la expulsión de 1609] L.B.P.

SORIA MESA, Enrique, «Don Alonso de Granada Venegas y la rebelión de los moriscos. Correspondencia y mercedes de don Juan de Austria», Chronica Nova, Granada, 21 (1993-1994):547-560.

SORIA MESA, Enrique, «La venta de bienes de la casa real. El caso de Gor bajo Muhammad El Izquierdo», Miscelánea de Estudios Arabes y Hebraicos, Granada, XLII-XLIII (1993-1994):291-304.

SORIA MESA, Enrique, «La asimilación de la élite morisca en la Granada cristiana. El ejemplo de la familia Hermes», en: Mélanges Louis Cardaillac, II.649-658.

[Ejemplo de integración de una familia conversa de clase media-alta (comerciantes de seda) en las clases altas de la Granada cristiana, primero acercándose a las grandes familias moriscas granadinas y más tarde enlazando con familias cristianas viejas también de clase media-alta] L.B.P.

Soto Pelayo, J. - Oliver PallarRes, T., «Aproximación al estudio sobre la transformación de los sistemas irrigatorios de Almería, tras la conquista cristiana», 1490: En el umbral de la modernidad. El Mediterráneo europeo y las ciudades en el tránsito de los siglos XV-XVI, Valencia, Generalitat Valenciana, 1994, vol. II, pp. 659-668.

SZMOLKA ClARES, José, «Los inicios de una imposible convivencia: La Granada mudéjar (1492-1502)», en: Mélanges Louis Cardaillac, II.659-674.

[Visión detenida acerca de los mecanismos administrativos aplicados en Granada después de su conquista por los Reyes Católicos. A la visión medieval de las primeras capitulaciones sucedió una política de restricción y repoblaciones -uno de los orígenes de disturbios posteriores- que culminará en la conversión obligatoria de los mudéjares granadinos] L.B.P.

TAPIA, Serafín de, «Las redes comerciales de los moriscos en Castilla la Vieja. Un vehículo para sus 'complicidades'», Studia Historica, Salamanca, XI, 1993, 231-243.

[Especialmente por sus relaciones con los reinos de Granada, Navarra y Aragón, a lo largo del siglo XVI] M.E. 
TEMIMI, Abdeljelil

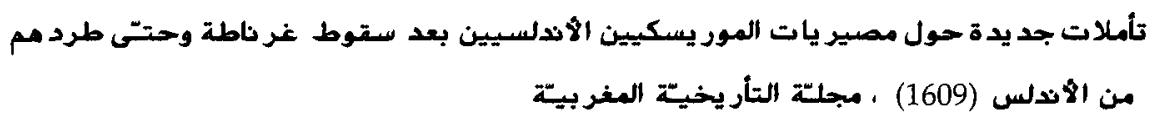

Revue d'Histoire Maghrebine, 75-76 (1994): 353-360.

[«Nuevas reflexiones sobre el destino de los moriscos después de la caída de Granada hasta su expulsión de al-Andalus (1609)»].

TEMIMI, Abdeljelil (ed.), Bibliographie Générale d'Études Morisques, Zaghouan, CEROMDI, 1995.

TEMIMI, Abdeljelil (ed.), Mélanges Louis Cardaillac, Zaghouan, FTERSI, 1995, 2 vols.

TEMIMI, Abdeljelil, «Politique ottomane face à l'expulsion des Morisques et à leur passage en France et à Venise. 1609-1610», en: Mélanges Louis Cardaillac, II.675-698.

[Nueva correspondencia descubierta entre el sultán otomano Ahmad I y María de Médicis y el Dogo de Venecia acerca de la preocupación del primero por que los moriscos puedan atravesar con seguridad los territorios franceses y venecianos para llegar a tierras musulmanas. Se destaca el papel jugado por el embajador francés en Istanbul Biron de Salignac. Siete apéndices documentales] L.B.P.

TRILlO SANJOSÉ, Carmen, La Alpujarra antes y después de la conquista castellana, Universidad de Granada, Granada, 1994, 423 pp (14×21 cm).

[Estudio documentado de esa región granadina, en época islámica y tras la conquista castellana de fines del $\mathrm{XV}$, especialmente en sus aspectos demográficos, económicos, políticos y militares. Apéndices documentales e índices] M.E.

TURKI, Muhammad, «Le rôle des morisques dans la transformation du milieu rural de la Tunisie du XVII ${ }^{\text {e }}$ siècle», en: Fatma Haddad-Chamakh - Alia Baccar-Bourmaz (eds.), L'écho de la prise de Grenade dans la culture européenne aux XVI ${ }^{\mathrm{e}}$ et XVII ${ }^{\mathrm{e}}$ siècles, Tunis, Cérès Editions - Ministère de l'Education et des Sciences, 1994, pp. 65-77.

TURKI, Muhammad, «Personnalité de l'Andalou-Morisque. Traits de caractères», en: Mélanges Louis Cardaillac, II.699-708.

[Partiendo de informaciones orales el autor intenta trazar, con relatos y anécdotas situadas en las ciudades tunecinas de implantación morisca, los caracteres esenciales de una "personalidad morisca" actual, hecho diferenciador con respecto a la población autóctona] L.B.P. 
'UNAN (ENAN, INAN), Muhammad Abdullah, «La historia de un escritor morisco», Lamalif. Al-Andalus, Almería, 5, 1992, 76-81.

[Artículo divulgativo sobre el morisco sevillano de origen granadino, funcionario marroquí y viajero, Ahmad Ibn Al-Qasim Shihab ad-Din Afuqay Al-Hayari Bejarano, y sobre sus escritos en árabe (siglo XVII)] M.E.

VALERO-CUADRA, Pino, «El mito literario medieval de la mujer sabia: la doncella Teodor», Las sabias mujeres. Educación, saber y autoría (siglos III-XVII) (Cristina SEGURA GRAíño, ed.), Madrid, 1994.

Valor Piechotta, M. - Casquete de Prado Sagrera, N., «El castillo de Cumbres Mayores (Huelva). Una aproximación a la arquitectura militar de la segunda mitad del s. XIII", Historia, Instituciones, Documentos, Sevilla, 21 (1994):473-500

[Rasgos de mudejarismo en dicho castillo] E.L.G.

VIDAL, Jeanne, «Los moriscos y la Inquisición: táctica inquisitorial y resistencia morisca», en: Mélanges Louis Cardaillac, II.709-720.

[A partir de documentación inquisitorial, repaso por las diferentes actitudes de resistencia de los moriscos ante el Santo Oficio, resistencia bien jurídica, bien física. Análisis de la evolución del comportamiento inquisitorial con los moriscos] L.B.P.

Viguera Molíns, María Jesús, «Un nuevo hallazgo: El manuscrito aljamiado de Urrea de Jalón», Lamalif. Al-Andalus, Almería, 5, 1992, 42-54.

[Presentación, con abundantes notas bibliográficas, del texto editado por F. Corriente y prologado por la misma autora (Zaragoza, 1990)] M.E.

Viguera Molíns, María Jesús

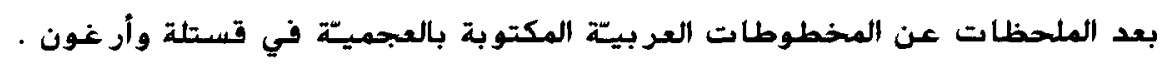

en: Ahmed-Chouqui Binebine (coord.), Le manuscrit arabe et la Codicologie, Rabat, Publications de la Faculté des Lettres et des Sciences Humaines Université Mohammed V, 1994, pp. 113-120.

[Algunos datos sobre manuscritos árabes con escritura aljamiada en Castilla y Aragón).

Viguera MOLÍNS, María Jesús, "Apuntes diversos en el manuscrito aljamiado de Urrea de Jalón», Aragón en la Edad Media, vol. X-XI, Zaragoza, Homenaje a la profesora emérita María Luisa Ledesma Rubio, 1993, 895-906. 
[Transcripción y estudio de los tres textos aljamiados aragoneses contenidos en una hoja independiente que apareció en el ms. aljamiado de Urrea de Jalón, ya estudiado por la autora y editado por F. Corriente (1990): el Credo, una iguala y un ensalmo para la fiebre] L.B.P.

VINCENT, Bernard, «L'État espagnol et le refus de l'autre», en: Fatma Haddad-Chamakh - Alia Baccar-Bourmaz (eds.), L'écho de la prise de Grenade dans la culture européenne aux XVI et XVII siècles, Tunis, Cérès Editions Ministère de l'Education et des Sciences, 1994, pp. 337-343.

VINCENT, Bernard, «Le nonce et les Morisques», en: Mélanges Louis Cardaillac, II.735-738.

[Análisis del contenido de las cartas enviadas a Roma por el nuncio Castagna entre 1569 y 1570, acerca de los acontecimientos y los problemas de la guerra de las Alpujarras] L.B.P.

VINCENT, Bernard, «Le repeuplement du Royaume de Grenade (1570-1580)», Settimana "Le Migrazione", Pratto, 1993, 383-393.

[Estudio de los orígenes regionales de los "cristianos viejos" que se instalaron en el Reino de Granada tras la expulsión de los moriscos, consecuencia de la Guerra de Las Alpujarras. Cuadros estadísticos, comarca por comarca, con reflexiones generales] M.E.

VINCENT, Bernard, «Les émigrations morisques», 1st European Conference of the International Comission on Historical Demography, Conselleria de Educación e Ordenación Universitaria, Santiago de Compostela, 1993, 327-325.

[Presentación general de los cambios demográficos propiciados por las expulsiones de musulmanes españoles del XVI-XVII, hacia Europa y el mundo islámico, especialmente hacia el Mágreb. Sin notas] M.E.

Siglas de recesionados: E.L.G., Eva Lapiedra Gutiérrez; L.B.P., Luis F. Bernabé Pons; M.E., Míkel de Epalza. 